\title{
Symptomatology of COVID-19 from the otorhinolaryngology perspective: a survey of 223 SARS-CoV-2 RNA-positive patients
}

\author{
Egehan Salepci ${ }^{1}$ (]) Bilge Turk ${ }^{1} \cdot$ Safiye Nur Ozcan ${ }^{2} \cdot$ Merve Ekici Bektas $^{1} \cdot$ Alperen Aybal $^{1} \cdot$ llyas Dokmetas $^{2}$. \\ Suat Turgut ${ }^{1}$
}

Received: 24 June 2020 / Accepted: 10 August 2020 / Published online: 13 August 2020

(c) Springer-Verlag GmbH Germany, part of Springer Nature 2020

\begin{abstract}
Purpose To determine prevalence, severity, duration, and time from onset to diagnosis of general and Otorhinolaryngologic symptoms related to COVID-19 in whole disease spectrum: from mild to critical patients.

Methods All adult patients with positive SARS-CoV-2 RNA found in nasopharyngeal and oropharyngeal swabs between March 10 and April 21, 2020 were surveyed by the authors for new onset symptoms during disease course. Demographic features, general symptoms, and Otorhinolaryngological symptoms were evaluated and compared by disease severity.

Results Of 223 included patients, $18.4 \%$ had mild, 61.4\%; moderate, $14.3 \%$; severe, and 5.8\%; critical disease. Median age was 51 (range 20-93), 113 (50.7\%) were male and 110 (49.3\%) were female. The most common general symptoms were fatigue, cough, and fever with respective frequencies of $71.3 \%, 54.3 \%$, and $50.7 \%$. The most common Otorhinolaryngologic symptoms were taste loss, smell loss, and sore throat with respective frequencies of $34.5 \%, 31.8 \%$, and $26 \%$. Fatigue, fever, and dyspnea were more common in severe-critical patients compared to mild-moderate patients $(p=0.029, p=0.016$, and $p<0.001$, respectively). Only smell loss was more common in mild-moderate group $(p=0.003)$. Prevalence of other symptoms did not differ between groups. Symptom durations and onset time to diagnosis varied.

Conclusion When compared to the previous studies, while general symptoms were less common, Otorhinolaryngologic symptoms were more common in our study population. Considering high infection risks, Otorhinolaryngologists should be aware of COVID-19 patients presenting with Otorhinolaryngologic complaints.
\end{abstract}

Keywords COVID-19 $\cdot$ Respiratory symptoms $\cdot$ ENT symptoms $\cdot$ Smell loss $\cdot$ Taste loss

\section{Introduction}

At the end of 2019 in Wuhan, Severe Acute Respiratory Syndrome Coronavirus 2 (SARS-CoV-2) was defined as the cause of a novel lower respiratory tract infection. On

Electronic supplementary material The online version of this article (https://doi.org/10.1007/s00405-020-06284-1) contains supplementary material, which is available to authorized users.

Egehan Salepci

egehansalepci@yahoo.com

1 Department of Otorhinolaryngology, University of Health Sciences, Sisli Hamidiye Etfal Training and Research Hospital, Etfal Sk. No: 1, 34371 Sisli, Istanbul, Turkey

2 Department of Clinical Microbiology and Infectious Diseases, University of Health Sciences, Sisli Hamidiye Etfal Training and Research Hospital, 34371 Sisli, Istanbul, Turkey
February 11, 2020 World Health Organization (WHO) officially named the disease as Coronavirus Disease 2019 (COVID-19) [1, 2]. After WHO officially declared the disease a pandemic on March 11, 2020, many reports showed high infection rates among healthcare workers. Working constantly on mucosal surfaces with high viral loads, it became apparent that Otorhinolaryngologists were at higher risk [3]. Loss of an Otorhinolaryngologist as the first reported physician death stressed the severity of the situation [4].

First reports from China described the disease as a lower respiratory tract infection. Common symptoms were fever, cough, and shortness of breath. Upper respiratory symptoms such as sore throat or rhinorrhea were uncommon in these first reports. Major limitation of these studies is that they were conducted on hospitalized patients who had worse forms of the disease [5-10]. Following studies from other countries reported higher incidence of upper respiratory 
symptoms and lately smell loss has become a prominent future of the disease [11-18].

Although cited studies provided valuable information regarding symptomatology of COVID-19, to the best of our knowledge, no study addressed Otorhinolaryngologic manifestations in whole disease spectrum: from mild to critical patients. In that regard, we aimed to survey every patient that tested positive for SARS-CoV-2 ribonucleic acid (RNA) and substantiate prevalence, duration, severity, and days from onset to diagnosis of general and Otorhinolaryngologic symptoms. As Otorhinolaryngologists are more prone to care for patients with milder forms of the disease, we also wanted to assess whether symptoms differed in this subset compared to severe forms [19].

\section{Methods}

\section{Setting}

This cross-sectional study was conducted at University of Health Sciences, Sisli Hamidiye Etfal Training and Research Hospital in Istanbul, Turkey after institutional ethics committee approved the research plan (Date: April 22, 2020, Number: 2730). Written informed consents were obtained from all participants. We assessed patients who had SARSCoV-2 RNA detected by reverse transcription polymerase chain reaction (RT-PCR) in their nasopharyngeal or oropharyngeal swab specimens. A total of 223 patients (113 males, 110 females) were included.

\section{Patient selection and classification}

During the time interval of the study, all patients with suspicion of COVID-19 were managed according to interim guidelines published by the Ministry of Health of Turkey Study Board. This guide was updated regularly as new information became available. Resident or attending doctors collected nasopharyngeal and oropharyngeal swabs after a short training following actual interim guide. Specimens were tested for the presence of SARS-CoV-2 RNA by Nucleic Acid Amplification Tests (RT-PCR and nucleic acid sequence analysis when necessary) in the General Directorate of Public Health Microbiology Reference Laboratory [20].

We searched the tertiary care center University of Health Sciences, Sisli Hamidiye Etfal Training and Research Hospital Database for adult patients (Age $>18$ years) with initial diagnoses of COVID-19 between March 10 and April 21, 2020. We did not include pediatric population in our study, because classification and management of pediatric COVID19 cases differed significantly in interim guides [20, 21]. Patients under the age of 18 , those who could not be reached, refused to participate in the study or unable to complete to survey due to underlying health conditions were excluded. The flow diagram for patient recruitment and exclusion and clinical distribution of included patients is provided as Fig. 1.

We classified patients groups according to disease severity as directed by the national interim guidance and World Health Organization (WHO) interim clinical management guidance (Table 1) [20, 21]. Considering recent studies that suggest Otorhinolaryngologic symptoms were more common in patients with mild and moderate disease; we combined these two groups together as mild-moderate [19]. Similarly, we grouped patients in critical and severe groups together as critical-severe for comparison.

\section{Survey design}

After reviewing the literature for reported general and Otorhinolaryngologic symptoms of COVID-19, we prepared a questionnaire for the survey (an English translated version of questionnaire used is provided as Online Resource 1). Commonly reported general symptoms were determined as fever, cough, myalgia/arthralgia, dyspnea, fatigue, and headache. Relevant Otorhinolaryngologic symptoms were found as smell loss, taste loss, sore throat, frontal type headache, rhinorrhea, and nasal congestion [5-8]. There were not yet reports of earache, loss of hearing, facial paralysis, or dizziness during the survey design. We included these symptoms, because they can accompany other well-studied viral diseases [22-24].

\section{Patient interviews}

Each patient was contacted by the authors: in person if patient was still hospitalized, by phone otherwise. All patients signed the informed consents forms. If patient was discharged during the interview, consents forms were filled online. Author conducting the interview filled the survey form, patients were not asked to fill it by themselves.

Surveying authors first asked the patients to describe their complaints, and then explained each symptom in detail to reduce confusions in context. If the patient had the symptom for longer than 2 months before the hospital referral, it was judged unrelated to COVID-19. Symptom severity was assessed using the Visual Analogue Scale (VAS); a subjective scale of $0-10$, with 0 denoting "no symptoms" and 10 "severe symptoms" by asking the patients to consider the time symptoms were the worst to score severity. They were also asked about the onset time of the symptoms to assess symptom duration and time from onset to diagnosis.

Patients who had comorbidities such as Chronic Obstructive Pulmonary Disease (COPD), asthma, or heart failure that could cause symptoms to be chronically present were 
Fig. 1 Patient enrollment process and clinical distribution of patients

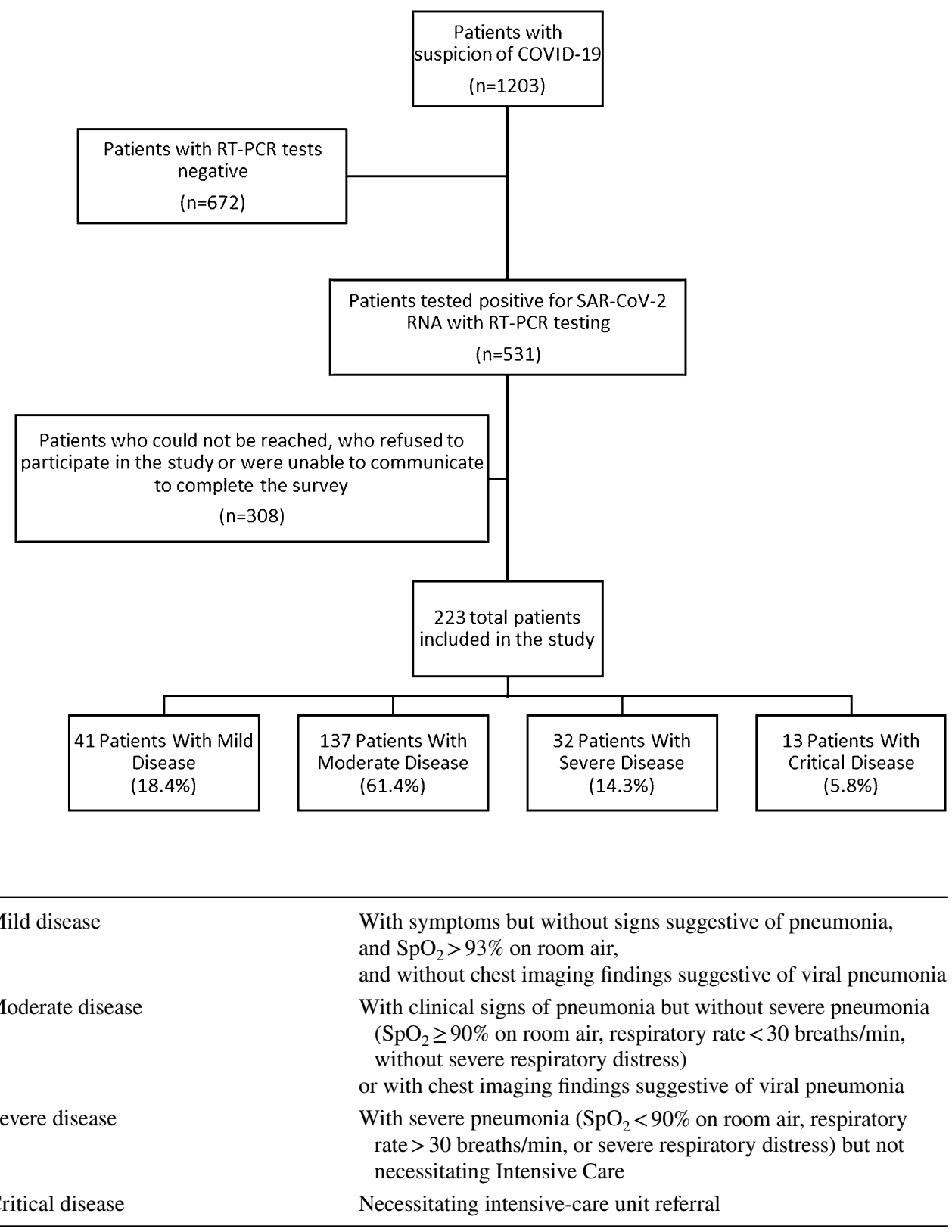

$\mathrm{SpO}_{2}$ Oxygen saturation
Table 1 Disease severity classification criteria

\begin{tabular}{ll}
\hline Mild disease & $\begin{array}{l}\text { With symptoms but without signs suggestive of pneumonia, } \\
\text { and } \mathrm{SpO}_{2}>93 \% \text { on room air, } \\
\text { and without chest imaging findings suggestive of viral pneumonia }\end{array}$ \\
With clinical signs of pneumonia but without severe pneumonia \\
Moderate disease & $\mathrm{SpO}_{2} \geq 90 \%$ on room air, respiratory rate $<30$ breaths/min, \\
& without severe respiratory distress $)$ \\
or with chest imaging findings suggestive of viral pneumonia & With severe pneumonia $\left(\mathrm{SpO}_{2}<90 \%\right.$ on room air, respiratory \\
rate $>30$ breaths/min, or severe respiratory distress) but not \\
necessitating Intensive Care
\end{tabular}

asked about aggravation rather than presence of such symptoms. During the interviews, it was also made sure that Otorhinolaryngologic symptoms were of new onset and were not explained by any other underlying disease. If patients had ongoing symptoms during the interview, they were contacted via a phone call 1 month later for reassessment. If they still had disease-related complaints at that time, these symptoms were blinded for duration analysis and reported separately.

Of note is that we used the symptom definition as a distress perceived by the patient. We did not report objective variables related to symptoms such as measured body temperature. In that context, presence of fever means: feelings of chills, body temperature changes, or self-measured body temperatures above $38.3{ }^{\circ} \mathrm{C}[25,26]$.

\section{Statistical analysis}

All statistical analyses were conducted by SPSS (Version 22.0, Chicago, IL, USA). Continuous variables were expressed as means and standard deviation when normality criteria were met, otherwise as median and ranges. Categorial variables were reported as numbers and percentages. Chi-square test was used to compare categorical variables with Fisher's exact test as needed. Mann-Whitney $U$ test 
was used to compare continuous variables, Statistical significance level was taken as $p<0.05$ (two-sided).

When charting boxplots for duration and symptom onset to diagnosis interval; missing symptoms were excluded variable by variable rather than listwise to increase visualization of data.

\section{Results}

Between March 10 and April 21, 2020, 1203 adult patients were tested with suspicion of COVID-19 in our institution. 531 patients had positive tests for SARS-CoV-2 RNA. Of those, 223 patients who met inclusion criteria were enrolled in the study. When we assessed study population for symptomatic distribution, we found that 13 did not have any symptoms $(5.8 \%), 9(4 \%)$ had only Otorhinolaryngologic symptoms, 65 (29.1\%) had only general symptoms, and 136
(61.5\%) had both general and Otorhinolaryngologic symptoms. Thirteen asymptomatic patients had positive Computed Tomography (CT) scan findings, so they were grouped in the moderate-disease group.

Patients in mild-moderate-disease group were younger, less likely to have positive lung CT scan findings, and less likely to be hospitalized ( $p<0.001, p=0.007$ and $p<0.001$ respectively). Percentage of males was similar between groups. Median days from first symptom onset to hospitalization did not differ (Table 2). Hypertension and diabetes mellitus were more common in severe-critical group ( $p<0.001$ and $p=0.042$, respectively). The presence of other comorbidities were similar (Table 3 ).

Symptom frequencies, severities, and durations across patients are summarized in Table 4 . The most common general symptom was fatigue (71.3\%) followed by cough (54.3\%), and fever (50.7\%). Taste loss, smell loss, and sore throat were common Otorhinolaryngologic symptoms with

Table 2 Patient characteristics, hospitalization status, CT findings, and days from first symptom onset to diagnosis by disease severity

\begin{tabular}{|c|c|c|c|c|c|c|c|}
\hline & \multicolumn{2}{|l|}{$\begin{array}{l}\text { All patients } \\
(N=223)\end{array}$} & \multicolumn{2}{|c|}{$\begin{array}{l}\text { Mild-moderate disease } \\
(N=178)\end{array}$} & \multicolumn{2}{|c|}{$\begin{array}{l}\text { Severe-critical disease } \\
(N=45)\end{array}$} & \multirow[t]{2}{*}{$p$ value } \\
\hline & Median or $n$ & IQR or $\%$ & Median or $n$ & IQR or $\%$ & Median or $n$ & IQR or $\%$ & \\
\hline Age & 51 & $36-62$ & 48 & $33-59$ & 62 & $52-71.50$ & $<0.001$ \\
\hline Sex (male) & 113 & $50.7 \%$ & 88 & $49.4 \%$ & 25 & $55.6 \%$ & 0.463 \\
\hline Hospitalization status & 162 & $72.6 \%$ & 117 & $65.7 \%$ & 45 & $100 \%$ & $<0.001$ \\
\hline CT findings compatible with COVID-19 & 182 & $85 \%$ & 138 & $81.7 \%$ & 44 & $97.8 \%$ & 0.007 \\
\hline Days from first symptom onset to diagnosis & 3 & $0-7$ & 3 & $0-7$ & 3 & $1-6.5$ & 0.422 \\
\hline
\end{tabular}

$N$ patient number in group, $n$ patient number with the trait, $I Q R$ interquartile range

$P$ value for mild disease group vs. severe disease group

Table 3 Patient comorbidities by disease severity

\begin{tabular}{|c|c|c|c|c|c|c|c|}
\hline & \multicolumn{2}{|c|}{$\begin{array}{l}\text { All patients } \\
(N=223)\end{array}$} & \multicolumn{2}{|c|}{$\begin{array}{l}\text { Mild-moderate } \\
\text { disease } \\
(N=178)\end{array}$} & \multicolumn{2}{|c|}{$\begin{array}{l}\text { Severe-critical } \\
\text { disease } \\
(N=45)\end{array}$} & \multirow[t]{2}{*}{$p$ value } \\
\hline & $n$ & $\%$ & $n$ & $\%$ & $n$ & $\%$ & \\
\hline Hypertension & 74 & 33.2 & 49 & 27.5 & 25 & 55.6 & $<0.001$ \\
\hline Diabetes mellitus & 41 & 18.4 & 28 & 15.7 & 13 & 28.9 & 0.042 \\
\hline Chronic lung disease & 18 & 8.1 & 12 & 6.7 & 6 & 13.3 & 0.147 \\
\hline Coronary artery disease & 17 & 7.6 & 13 & 7.3 & 4 & 8.9 & 0.754 \\
\hline Renal disease & 12 & 5.4 & 7 & 3.9 & 5 & 11.1 & 0.069 \\
\hline Previous nasal surgery & 9 & 4 & 8 & 4.5 & 1 & 2.2 & 0.691 \\
\hline Autoimmune disease & 7 & 3.1 & 5 & 2.8 & 2 & 4.4 & 0.631 \\
\hline Chronic rhinosinusitis & 7 & 3.1 & 1 & 2.2 & 6 & 3.4 & 1 \\
\hline Neurologic disease & 5 & 2.2 & 4 & 2.2 & 1 & 2.2 & 1 \\
\hline Cancer & 4 & 1.8 & 2 & 1.1 & 2 & 1.8 & 0.182 \\
\hline Cerebrovascular disease & 2 & 0.6 & 1 & 0.6 & 1 & 2.2 & 0.364 \\
\hline Previous oropharyngeal surgery & 2 & 0.9 & 2 & 1.1 & 0 & 0 & 1 \\
\hline
\end{tabular}

$N$ patient number in group, $n$ patient number with the trait $p$ value for mild disease group vs. severe disease group 
Table 4 Patient symptom frequencies, severities, and durations

\begin{tabular}{|c|c|c|c|c|c|c|c|}
\hline & \multicolumn{2}{|l|}{$\begin{array}{l}\text { All patients } \\
(N=223)\end{array}$} & \multicolumn{2}{|c|}{$\begin{array}{l}\text { Mild-moderate disease } \\
(N=178)\end{array}$} & \multicolumn{2}{|c|}{$\begin{array}{l}\text { Severe-critical disease } \\
(N=45)\end{array}$} & \multirow[t]{2}{*}{$p$ value } \\
\hline & Median or $n$ & IQR or $\%$ & Median or $n$ & IQR or $\%$ & Median or $n$ & IQR or $\%$ & \\
\hline \multicolumn{8}{|l|}{ General symptoms } \\
\hline \multicolumn{8}{|l|}{ Fatigue } \\
\hline Frequency & 159 & $71.3 \%$ & 121 & $68 \%$ & 38 & $84.4 \%$ & 0.029 \\
\hline Severity $(1-10)$ & 8 & $5-10$ & 7 & $5-9$ & 8 & $7-10$ & 0.042 \\
\hline Duration (Days) & 10 & $6-15$ & 9 & $6-12.5$ & 13 & $8.5-22.5$ & $<0.001$ \\
\hline \multicolumn{8}{|l|}{ Cough } \\
\hline Frequency & 121 & $54.3 \%$ & 91 & $51.1 \%$ & 30 & $66.7 \%$ & 0.062 \\
\hline Severity (1-10) & 5 & $4-8$ & 5 & $5-8$ & 5 & $3.75-7.25$ & 0.032 \\
\hline Duration (days) & 12 & $7-20$ & 11 & $7-18.5$ & 17 & $8-30$ & 0.059 \\
\hline \multicolumn{8}{|l|}{ Fever } \\
\hline Frequency & 113 & $50.7 \%$ & 83 & $46.6 \%$ & 30 & $66.7 \%$ & 0.016 \\
\hline Severity (1-10) & 6 & $5-8$ & 6 & $5-7$ & 7.5 & $5-9.25$ & 0.009 \\
\hline Duration (days) & 5 & $2.25-9.75$ & 4 & $2-9$ & 7 & $4-12$ & 0.008 \\
\hline \multicolumn{8}{|l|}{ Myalgia/arthralgia } \\
\hline Frequency & 113 & $50.7 \%$ & 91 & $51.1 \%$ & 22 & $48.9 \%$ & 0.789 \\
\hline Severity (1-10) & 7 & $5-9$ & 7 & $5-8$ & 7 & $5-10$ & 0.478 \\
\hline Duration (days) & 8 & $5-13$ & 7 & $5-12$ & 11.5 & $7-17$ & 0.051 \\
\hline \multicolumn{8}{|l|}{ Dyspnea } \\
\hline Frequency & 84 & $37.7 \%$ & 52 & $29.2 \%$ & 32 & $71.1 \%$ & $<0.001$ \\
\hline Severity (1-10) & 5 & $3.25-8$ & 5 & $4-8$ & 7 & $3-8$ & 0.215 \\
\hline Duration (days) & 7 & $3-16$ & 5 & $2-10$ & 12 & $6-20$ & 0.005 \\
\hline \multicolumn{8}{|l|}{ Headache } \\
\hline Frequency & 59 & $26.5 \%$ & 48 & $27 \%$ & 11 & $24.4 \%$ & 0.732 \\
\hline Severity $(1-10)$ & 6 & $5-8$ & 6 & $5-8$ & 8 & $4-8$ & 0.514 \\
\hline Duration (days) & 6 & $3-11$ & 5.5 & $3-10.75$ & 7 & $4-12$ & 0.725 \\
\hline \multicolumn{8}{|c|}{ Otolaryngologic symptoms } \\
\hline \multicolumn{8}{|l|}{ Taste loss } \\
\hline Frequency & 77 & $34.5 \%$ & 65 & $36.5 \%$ & 12 & $26.7 \%$ & 0.214 \\
\hline Severity (1-10) & 8 & $5-10$ & 8 & $5-10$ & 8.5 & $4-10$ & 0.555 \\
\hline Duration (days) & 8 & $5-12$ & 7 & $5-11$ & 11 & $7.25-16$ & 0.081 \\
\hline \multicolumn{8}{|l|}{ Smell loss } \\
\hline Frequency & 71 & $31.8 \%$ & 65 & $36.5 \%$ & 6 & $13.3 \%$ & 0.003 \\
\hline Severity $(1-10)$ & 8 & $5-10$ & 8 & $5-10$ & 6.5 & $3.75-10$ & 0.327 \\
\hline Duration (days) & 8 & $6-13.5$ & 8 & $5-11$ & 15 & $10.75-18.5$ & 0.013 \\
\hline \multicolumn{8}{|l|}{ Sore throat } \\
\hline Frequency & 58 & $26 \%$ & 47 & $26.4 \%$ & 11 & $24.4 \%$ & 0.789 \\
\hline Severity (1-10) & 5 & $4-6$ & 4.5 & $4-5$ & 5 & $3-7$ & 0.642 \\
\hline Duration (days) & 5 & $3-10.5$ & 5 & $3-10$ & 9 & $5-22$ & 0.072 \\
\hline \multicolumn{8}{|l|}{ Nasal congestion } \\
\hline Frequency & 37 & $16.6 \%$ & 30 & $16.9 \%$ & 7 & $15.6 \%$ & 0.834 \\
\hline Severity (1-10) & 5 & $4-7$ & 5 & $4-7$ & 7 & $3-8$ & 0.481 \\
\hline Duration (days) & 8 & $4-13.5$ & 8 & $4-10.5$ & 13 & $2-24$ & 0.235 \\
\hline \multicolumn{8}{|l|}{ Dry throat } \\
\hline Frequency & 36 & $16.1 \%$ & 27 & $15.2 \%$ & 9 & $20 \%$ & 0.431 \\
\hline Severity (1-10) & 5 & $4-8$ & 4 & $3-7$ & 7 & $5-8$ & 0.040 \\
\hline Duration (Days) & 6 & $4-11$ & 5 & $3-10$ & 11.5 & $6.75-24$ & 0.014 \\
\hline \multicolumn{8}{|l|}{ Rhinorrhea } \\
\hline Frequency & 26 & $11.7 \%$ & 20 & $11.2 \%$ & 6 & $13.3 \%$ & 0.695 \\
\hline
\end{tabular}


Table 4 (continued)

\begin{tabular}{|c|c|c|c|c|c|c|c|}
\hline & \multicolumn{2}{|l|}{$\begin{array}{l}\text { All patients } \\
(N=223)\end{array}$} & \multicolumn{2}{|c|}{$\begin{array}{l}\text { Mild-moderate disease } \\
(N=178)\end{array}$} & \multicolumn{2}{|c|}{$\begin{array}{l}\text { Severe-critical disease } \\
(N=45)\end{array}$} & \multirow[t]{2}{*}{$p$ value } \\
\hline & Median or $n$ & IQR or $\%$ & Median or $n$ & IQR or $\%$ & Median or $n$ & IQR or $\%$ & \\
\hline Severity (1-10) & 4.5 & $3-5.25$ & 5 & $3.25-5$ & 3 & $2-6.25$ & 0.407 \\
\hline Duration (days) & 5 & $2.75-12.75$ & 5 & $2.25-9.75$ & 14.5 & $2.75-33.75$ & 0.133 \\
\hline \multicolumn{8}{|l|}{ Frontal headache } \\
\hline Frequency & 24 & $10.8 \%$ & 18 & $10.1 \%$ & 6 & $13.3 \%$ & 0.533 \\
\hline Severity $(1-10)$ & 5 & $4.25-8$ & 5 & $5-8$ & 6 & $3.75-8.5$ & 0.759 \\
\hline Duration (days) & 5 & $3.25-10$ & 5 & $3-10.5$ & 5.5 & $4-10.25$ & 0.686 \\
\hline \multicolumn{8}{|l|}{ Earache } \\
\hline Frequency & 6 & $2.7 \%$ & 4 & $2.2 \%$ & 2 & $4.4 \%$ & 0.416 \\
\hline Severity (1-10) & 4 & $3-7.25$ & 4 & $3-7.25$ & N/A & N/A & N/A \\
\hline Duration (days) & 7.5 & $2.75-15.25$ & 6 & $2.25-9.75$ & N/A & N/A & N/A \\
\hline \multicolumn{8}{|l|}{ Dizziness/Vertigo } \\
\hline Frequency & 5 & $2.2 \%$ & 1 & $0.6 \%$ & 4 & $8.9 \%$ & 0.001 \\
\hline Severity (1-10) & 4 & $3.5-7.5$ & N/A & N/A & 5 & $4-8.25$ & N/A \\
\hline Duration (Days) & 7.5 & $2.75-14.5$ & N/A & N/A & N/A & N/A & N/A \\
\hline \multicolumn{8}{|l|}{ Loss of hearing } \\
\hline Frequency & 2 & $0.9 \%$ & 0 & $0 \%$ & 2 & $4.4 \%$ & 0.005 \\
\hline Severity (1-10) & N/A & N/A & N/A & N/A & N/A & N/A & N/A \\
\hline Duration (Days) & N/A & N/A & N/A & N/A & N/A & N/A & N/A \\
\hline \multicolumn{8}{|l|}{ Facial paralysis } \\
\hline Frequency & 0 & $0 \%$ & 0 & $0 \%$ & 0 & $0 \%$ & N/A \\
\hline Severity (1-10) & N/A & N/A & N/A & N/A & N/A & N/A & N/A \\
\hline Duration (Days) & N/A & N/A & N/A & N/A & N/A & N/A & N/A \\
\hline
\end{tabular}

$N$ patient number in group, $n$ patient number with the trait, IQR interquartile range, $N / A$ not applicable

$p$ value for mild disease group vs. severe disease group

respective frequencies of $34.5 \%, 31.8 \%$, and $26 \%$. Only 5 patients reported dizziness (2.2\%), 2 loss of hearing $(0.9 \%)$, and none facial paralysis $(0 \%)$. Highest general symptom severity was for fatigue with a median VAS score of 8 . Highest Otorhinolaryngologic symptom severities were for smell loss and taste loss with median VAS scores of 8 . Other median severity VAS scores ranged between 4 and 7 .

Percentage of patients with fatigue, fever, or dyspnea was significantly higher in the severe-critical group ( $p=0.029$, $p=0.016$, and $p<0.001$, respectively). Smell loss was more common in the mild-moderate-disease group $(p=0.003)$. Four of five patients that reported hearing loss and two patients that reported dizziness were in severe-critical group. Other symptoms were not different between groups. While median severity VAS scores for fatigue, fever, and dry throat were higher in severe--critical group, median was higher for cough in mild-moderate group. Other symptom severities were similar.

Figure 2 illustrates median symptom durations and interquartile ranges of the patients. Cough was the longest lasting symptom with a median of 12 days. Fatigue followed with a median duration of 10 days. Fatigue, fever, dyspnea, and dry throat lasted longer in severe-critical group $(p<0.001$, $p=0.008, p=0.005$ and $p=0.014$, respectively). Median duration for smell loss was longer in mild-moderate group $(p=0.013)$. Other symptom durations were similar between groups (Table 4). Ongoing symptoms of ten patients during the 1-month follow-up were not included in the duration analysis (Table 5).

We plotted median time interval between the hospital referral day and symptom onset for each symptom in Fig. 3. Smallest median time interval from symptom onset to diagnosis was for sore throat with 4 days before diagnosis. Median for fatigue, myalgia/arthralgia, and dry throat were 3. Median symptom onset time of dyspnea, smell loss, and taste loss was referral day. For other symptoms, median onset was 1 or 2 days before referral (Table 4).

\section{Discussion}

COVID-19 presents with many different clinical manifestations, ranging from asymptomatic cases to mild and severe disease-with or without pneumonia. In this study, 


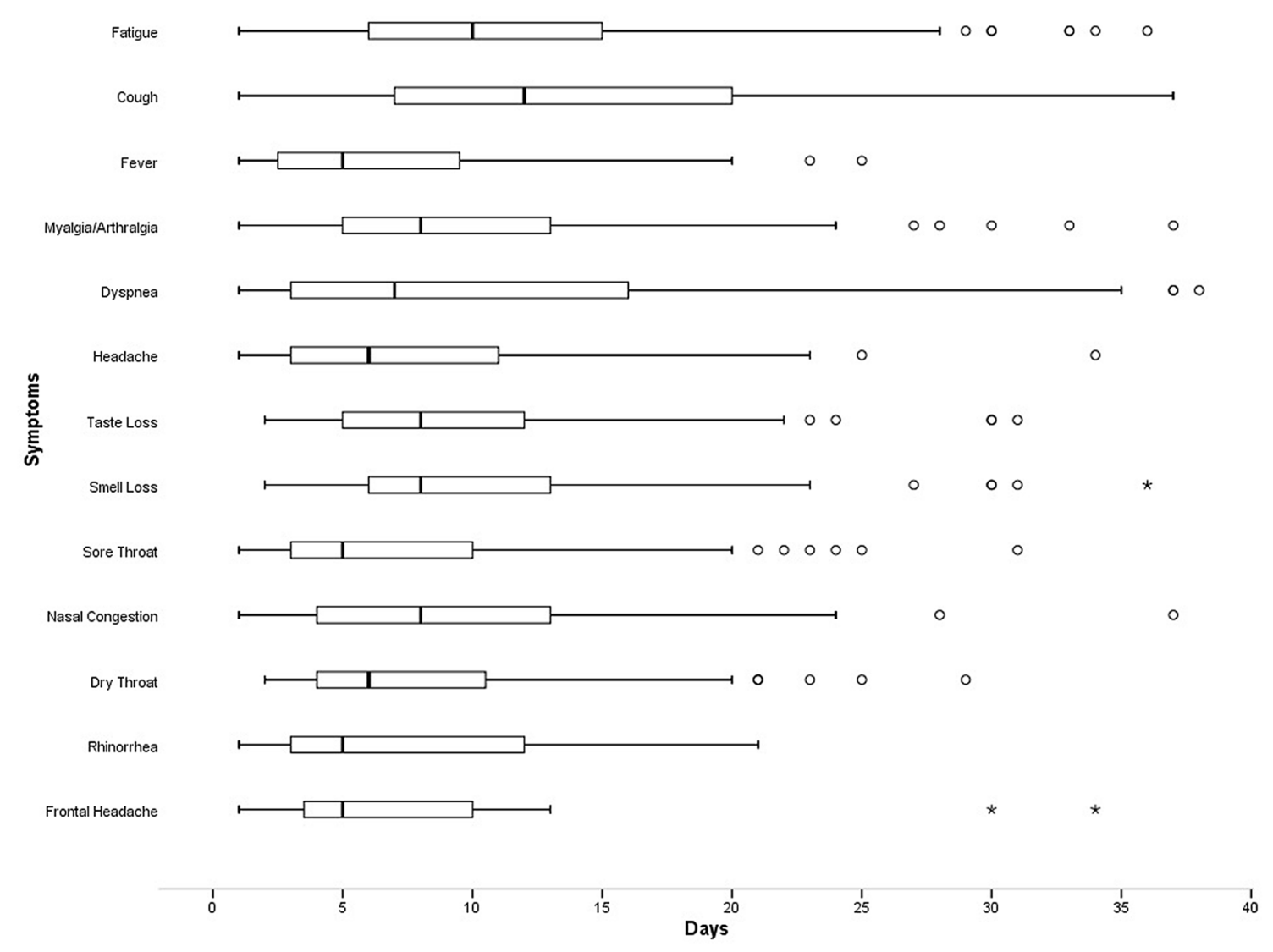

Fig. 2 Duration distribution of symptoms. Cases were excluded variable by variable

Table 5 Patient characteristics for ongoing symptoms during 1-month follow-up

\begin{tabular}{lll} 
Age Sex & $\begin{array}{l}\text { Follow-up day } \\
\text { after symptom } \\
\text { onset }\end{array}$ & Ongoing symptoms \\
\hline
\end{tabular}

\begin{tabular}{lllll}
\hline Patient 1 & 51 & Female & 52 & Smell loss, taste loss \\
Patient 2 & 26 & Female & 42 & Smell loss, taste loss \\
Patient 3 & 64 & Female & 52 & Myalgia/arthralgia \\
Patient 4 & 66 & Female & 70 & Smell loss \\
Patient 5 & 54 & Male & 39 & Cough, dry throat \\
Patient 6 & 36 & Male & 37 & Cough \\
Patient 7 & 52 & Female & 55 & Dyspnea \\
Patient 8 & 40 & Female & 45 & Smell loss \\
Patient 9 & 71 & Female & 38 & Smell loss \\
Patient 10 & 31 & Female & 45 & Smell loss, taste loss \\
\hline
\end{tabular}

we surveyed 223 patients with COVID-19 spanning whole disease spectrum. Clinical distribution of our patients is consistent with the largest case series from China that reported $81 \%$ mild disease, $14 \%$ severe disease, and $5 \%$ critical disease [27]. In that regard, the study succeeded in surveying the whole symptomatic patient population and had a representative sample. Also, by questioning every patient about specific symptoms, we reduced the possibility that patients with more severe forms of the disease might neglect minor symptoms.

Taste loss, smell loss, and sore throat were common Otorhinolaryngologic symptoms found in more than a quarter of patients. Frequencies of general symptoms such as fever, cough, and shortness of breath were much lower than first reports. Not surprisingly fever, dyspnea, and fatigue were significantly more common among severe-critical groups ( $p=0.016, p<0.001$ and $p=0.029$ respectively). Actually, numbers were closer to reports from China in this subset, consistent with the idea that the first reports were descriptive of patients with more severe forms of the disease [7].

By a letter to the editor; Lovato et al. criticized metaanalysis by Sun et al.- which is the largest meta-analysis study on COVID-19 to date-suggesting that true prevalence of sore throat was underestimated [5, 28]. In a followup systemic review, Lovato et al. reported that $12.4 \%$ of patients had sore throat. They also stated that most of the studies included in the review only assessed hospitalized patients. This was a limitation of their review [9]. In our study, sore throat prevalence was $26 \%$. Nasal congestion, dry throat, and rhinorrhea prevalence $(16.6 \%, 16.1 \%$, and $11.7 \%$, 


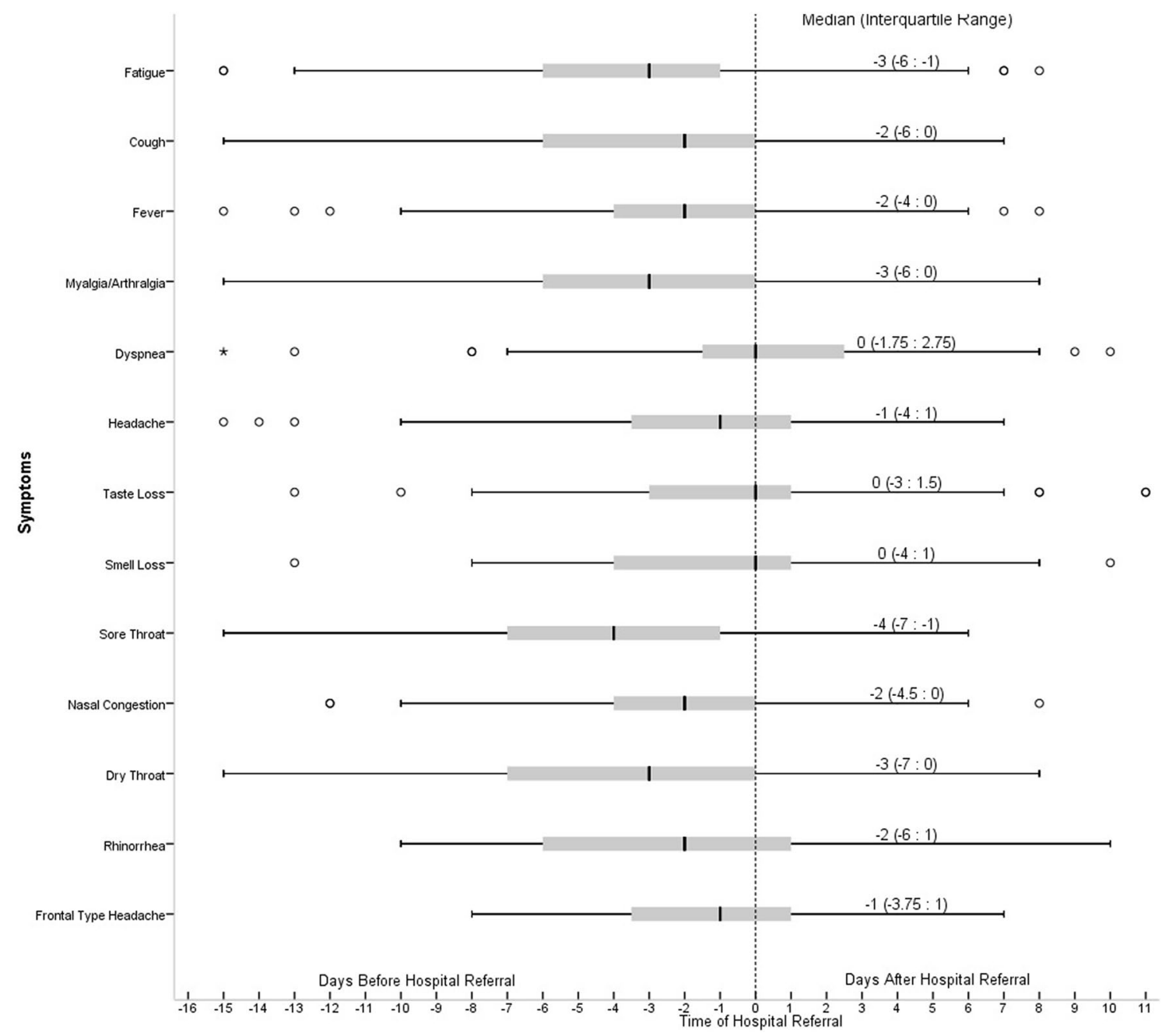

Fig. 3 Distribution of time intervals between symptom onset and diagnosis. Cases were excluded variable by variable

respectively) were also higher than previously cited reports. These findings suggest that the previous studies on hospitalized patients might have underestimated such symptoms too.

Most Otorhinolaryngologic symptom prevalence was similar across groups. Only smell loss prevalence was significantly higher in mild-moderate group $(p=0.003)$. These findings support the hypothesis that symptoms might not be mentioned by the patients if not asked directly-especially by severe and critical patients [29]. Only five patients stated that they had new onset complaints of dizziness and two that of hearing loss. It is possible that these complaints might not actually be related to COVID-19, but coincided with disease onset. Studies on wider populations might clarify this issue.

Our data show that time from symptom onset to diagnosis varies widely as apparent with wide interquartile ranges and error bars in Fig. 3. In the study population, earliest median symptom onset was for sore throat with 4 days before diagnosis. Fatigue, myalgia/arthralgia, and dry throat had median onset of 3 days before diagnosis. Lower respiratory symptoms fever and cough-which alert clinicians for the presence of pneumonia and COVID-19-had median onsets of 2 days before diagnosis. For dyspnea, median onset time was the day of diagnosis. These findings suggest a possible time frame that patients might have upper respiratory symptoms but no other well-known symptoms of the disease. This is an especially alarming finding as these patients might refer to Otorhinolaryngology clinics, increasing transmission risk.

Another important finding of our study is that symptom duration distribution is also wide (Fig. 2). Interquartile ranges of symptom durations were wide implying major differences between patients. Longest median duration was of cough with 12 days. After 1-month follow-up, ten patients still had at least one ongoing symptom (Table 5). This suggests that patients with ongoing symptoms after discharge might present to Otorhinolaryngology clinics with extended symptoms such as cough. Aftermath of the first phase of COVID-19 might be especially challenging for Otorhinolaryngology clinics around the globe. 
There are many studies addressing smell and taste loss in the literature, each reporting different prevalence [19, 30-33]. A recent meta-analysis reported the prevalence of olfactory dysfunction as $52.73 \%$ and gustatory dysfunction as $43.93 \%$ [15]. In our population, smell loss was found in $31.8 \%$ and taste loss, in $34.5 \%$ of the patients. Median onset time of olfactory and gustatory dysfunctions as diagnosis day is also parallel to the previous findings in the literature [16]. Six patients still having smell or taste loss after 1 month is concerning: long-term follow-up of these patients was planned. As long-term data are unavailable, it is yet unknown how long symptoms would last or if they would be permanent or not.

Otorhinolaryngology clinics around the world are reorganizing outpatient services to sustain patient care and to minimize the transmission of the disease $[34,35]$. Because many Otorhinolaryngologic examinations are aerosol producing examinations, it is important to determine which patients are at higher risk of disease transmission and take necessary precautions accordingly [36, 37]. Findings of our study contribute to the literature in that regard: relying solely on fever measurements and questioning of patients only for general symptoms would create a sense of false confidence. This approach risks missing asymptomatic patients or mildmoderate COVID-19 patients who still might be shedding the virus $[38,39]$. Otorhinolaryngologists should not only be alert for general symptoms but also for Otorhinolaryngologic symptoms that could be associated with COVID19. The absence of more common symptoms should not be interpreted as the absence of the disease.

In our study, there are several limitations to note. Our study was designed to be descriptive only, so multivariate or regression analyzes were not conducted. As Table $2 \mathrm{dem}-$ onstrates, patients in the severe-critical group were older and more of them had comorbidities. That could explain some symptomatologic differences between groups. Such confounding factors should be considered when designing future prospective studies and investigating correlations. We could not include every symptom currently defined in the literature. Gastrointestinal or neurologic manifestations of the disease were not yet widely reported during the design of the survey [40,41]. Our study is dependent on self-reports and we did not make any objective measurements, so there is always room for recall bias. Finally, as we only included patients above 18 years old, our results should only be interpreted for this population.

Prospective studies combining patient complaints with objective measurements would be especially valuable to overcome these limitations. Long-term follow-up of COVID-19 patients by Otorhinolaryngologists is also important to better understand disease progression and whether there are permanent sequelae. Our duty as clinicians is to provide continuous and high-quality care for our patients.
Having a better understanding of a disease that have such a big impact on patient care will help physicians to reestablish close doctor-patient relationships [42]. Finally, providing current and correct information to the society is crucial to stop dissemination of false information. People should be aware of the common symptoms and act accordingly, selfisolating when in doubt and seeking medical attention when necessary.

\section{Conclusion}

Otorhinolaryngologic manifestations are not rare symptoms of COVID-19, especially in mild and moderate forms of the disease. The results of this study show that in addition to lower respiratory symptoms, many COVID-19 patients also have Otorhinolaryngologic complaints. Onset of these symptoms might be earlier than that of well-known symptoms such as cough or fever. Mild cases of COVID-19 without clinical pneumonia might represent clinical presentation of the disease in young and healthy individuals. Symptom durations are variable and, in some patients, symptoms such as smell loss might persist months after discharge. Otorhinolaryngologists should be aware of these to provide highquality care for patients and take necessary precautions to protect themselves.

Author contributions ES (Resident M.D.): design, data collection and processing, data analysis and interpretation, literature review, writing, and critical review; BT (Associate Professor M.D.): conception, design, supervision, data interpretation, and critical review; SNO (Resident M.D.): design, data collection, data interpretation, literature review, and critical review; MEB (Resident M.D.): data collection and processing, literature review, and critical review; AA (Resident M.D.): data collection and processing, literature review, and critical review; ID (Professor M.D., Chief of Clinical Microbiology and Infectious Diseases Clinic): design, supervision, and critical review; ST (Professor M.D., Chief of Otorhinolaryngology Clinic): proposal of research subject, conception, data interpretation, supervision, and critical review.

Funding No funding was received for the conduct of the study.

\section{Compliance with ethical standards}

Conflict of interest The authors declare that they have no conflict of interest.

Ethical approval All procedures performed in studies involving human participants were in accordance with the ethical standards of the institutional and/or national research committee (Local Ethical Committee, Approval Date: April 22, 2020, Number: 2730) and with the 1964 Helsinki declaration and its later amendments or comparable ethical standards.

Consent to participate Written informed consents were taken from all patients who were included in the study. 
Consent for publication Usage of provided data for publication purposes was included in consent form (Item 10 of written consent forms).

\section{References}

1. Bogoch II, Watts A, Thomas-Bachli A et al (2020) Pneumonia of unknown aetiology in Wuhan, China: potential for international spread via commercial air travel. J Travel Med. https://doi. org/10.1093/jtm/taaa008

2. Guo YR, Cao QD, Hong ZS et al (2020) The origin, transmission and clinical therapies on coronavirus disease 2019 (COVID-19) outbreak-an update on the status. Mil Med Res 7:1

3. Zou L, Ruan F, Huang M et al (2020) SARS-CoV-2 viral load in upper respiratory specimens of infected patients. N Engl J Med 382:1177-1179

4. Chan JYK, Wong EWY, Lam W (2020) Practical aspects of otolaryngologic clinical services during the 2019 novel coronavirus epidemic: an experience in Hong Kong. JAMA Otolaryngol Head Neck Surg 146:519

5. Sun P, Qie S, Liu Z et al (2020) Clinical characteristics of hospitalized patients with SARS-CoV-2 infection: a single arm meta-analysis. J Med Virol 92:612-617. https://doi.org/10.1002/ jmv. 25735

6. Guan W, Ni Z, Hu Y et al (2020) Clinical characteristics of coronavirus disease 2019 in China. N Engl J Med 382:1708-1720. https://doi.org/10.1056/NEJMoa2002032

7. Huang C, Wang Y, Li X et al (2020) Clinical features of patients infected with 2019 novel coronavirus in Wuhan, China. Lancet 395:497-506. https://doi.org/10.1016/S0140-6736(20)30183-5

8. Wang D, Hu B, Hu C et al (2020) Clinical characteristics of 138 hospitalized patients with 2019 novel coronavirus-infected pneumonia in Wuhan, China. JAMA J Am Med Assoc 323:1061-1069. https://doi.org/10.1001/jama.2020.1585

9. Lovato A, de Filippis C (2020) Clinical presentation of COVID19: a systematic review focusing on upper airway symptoms. Ear Nose Throat J. https://doi.org/10.1177/0145561320920762

10. Rodriguez-Morales AJ, Cardona-Ospina JA, Gutiérrez-Ocampo E et al (2020) Clinical, laboratory and imaging features of COVID19: a systematic review and meta-analysis. Travel Med Infect Dis. https://doi.org/10.1016/j.tmaid.2020.101623

11. Hopkins C, Surda P, Kumar N (2020) Presentation of new onset anosmia during the COVID-19 pandemic. Rhinology. https://doi. org/10.4193/Rhin 20.116

12. Angelo Vaira L, Hopkins C, Salzano G et al (2020) Olfactory and gustatory function impairment in COVID-19 patients: Italian objective multicenter-study. Head Neck. https://doi.org/10.1002/ hed.26269

13. Moein ST, Hashemian SMR, Mansourafshar B et al (2020) Smell dysfunction: a biomarker for COVID-19. Int Forum Allergy Rhinol. https://doi.org/10.1002/alr.22587

14. Paderno A, Schreiber A, Grammatica A et al (2020) Smell and taste alterations in Covid-19: a cross-sectional analysis of different cohorts. Int Forum Allergy Rhinol. https://doi.org/10.1002/ alr. 22610

15. Tong JY, Wong A, Zhu D et al (2020) The Prevalence of olfactory and gustatory dysfunction in COVID-19 patients: a systematic review and meta-analysis. Otolaryngol Head Neck Surg. https:// doi.org/10.1177/0194599820926473

16. Speth MM, Singer-Cornelius T, Obere M et al (2020) Olfactory dysfunction and sinonasal symptomatology in COVID-19: prevalence, severity, timing, and associated characteristics. Otolaryngol Head Neck Surg. https://doi.org/10.1177/0194599820929185
17. Israelsen SB, Kristiansen KT, Hindsberger B et al (2020) Characteristics of patients with covid-19 pneumonia at hvidovre hospital, March-April 2020. DanMed J

18. Vaira LA, Salzano G, Deiana G, De Riu G (2020) Anosmia and ageusia: common findings in COVID-19 patients. Laryngoscope. https://doi.org/10.1002/lary.28692

19. Lechien JR, Chiesa-Estomba CM, De Siati DR et al (2020) Olfactory and gustatory dysfunctions as a clinical presentation of mild-to-moderate forms of the coronavirus disease (COVID19): a multicenter European study. Eur Arch Oto-Rhino-Laryngol. https://doi.org/10.1007/s00405-020-05965-1

20. Turkish Ministry of Health Scientific Board (2020) COVID19 (SARS-CoV-2 Infection) Guide. https://hsgm.saglik.gov.tr/ depo/birimler/goc_sagligi/covid19/rehber/COVID-19_Rehbe ri20200414 eng_v4 002 14.05.2020.pdf. Accessed 6 Jun 2020

21. World Health Organization (2020) Clinical management of COVID-19. https://www.who.int/publications/i/item/clinicalmanagement-of-covid-19. Accessed 6 Jun 2020

22. Chen X, Fu YY, Zhang TY (2019) Role of viral infection in sudden hearing loss. J Int Med Res 47:2865-2872

23. Sathirapanya P, Fujitnirun C, Setthawatcharawanich $S$ et al (2018) Peripheral facial paralysis associated with HIV infection: a case series and literature review. Clin Neurol Neurosurg 172:124-129. https://doi.org/10.1016/j.clineuro.2018.06.033

24. Hui DSC, Wong PC, Wang C (2003) SARS: clinical features and diagnosis. Respirology 8:s20

25. Kass-Hout TA, Buckeridge D, Brownstein J et al (2012) Selfreported fever and measured temperature in emergency department records used for syndromic surveillance. J Am Med Informatics Assoc 19:775-776. https://doi.org/10.1136/amiaj nl-2012-000847

26. Atkins E (1982) Fever: Its history, cause, and function. Yale J Biol Med 55:283-289

27. Wu Z, McGoogan JM (2020) Characteristics of and important lessons from the Coronavirus Disease 2019 (COVID-19) outbreak in China: summary of a report of 72314 cases from the Chinese center for disease control and prevention. JAMA J Am Med Assoc 323:1239-1242

28. Lovato A, Rossettini G, de Filippis C (2020) Sore throat in COVID-19: comment on "Clinical characteristics of hospitalized patients with SARS-CoV-2 infection: a single arm metaanalysis”. J Med Virol. https://doi.org/10.1002/jmv.25815

29. Vaira LA, Deiana G, Fois AG et al (2020) Objective evaluation of anosmia and ageusia in COVID-19 patients: Single-center experience on 72 cases. Head Neck 42:1252-1258

30. Sedaghat AR, Gengler I, Speth MM (2020) Olfactory dysfunction: a highly prevalent symptom of COVID-19 with public health significance. Otolaryngol Head Neck Surg. https://doi. org/10.1177/0194599820926464

31. Lehrich BM, Goshtasbi K, Raad RA et al (2020) Aggregate prevalence of chemosensory and sinonasal dysfunction in SARS-CoV-2 and related coronaviruses. Otolaryngol Head Neck Surg. https://doi.org/10.1177/0194599820929278

32. Kaye R, Chang CWD, Kazahaya K et al (2020) COVID-19 anosmia reporting tool: initial findings. Otolaryngol Head Neck Surg. https://doi.org/10.1177/0194599820922992

33. Lechner M, Chandrasekharan D, Jumani K et al (2020) Anosmia as a presenting symptom of SARS-CoV-2 infection in healthcare workers-a systematic review of the literature, case series, and recommendations for clinical assessment and management. Rhinology. https://doi.org/10.4193/Rhin20.189

34. Wickemeyer JL, Billings KR, Valika TS (2020) Evolving management of COVID-19: a multi-institutional otolaryngology perspective. Otolaryngol Head Neck Surg. https://doi. org/10.1177/0194599820930244 
35. Tay JK, Lim WS, Loh WS, Loh KS (2020) Sustaining otolaryngology services for the long haul during the COVID-19 pandemic: experience from a tertiary health system. Otolaryngol Head Neck Surg. https://doi.org/10.1177/0194599820922983

36. Shuman AG (2020) Navigating the ethics of COVID-19 in otolaryngology. Otolaryngol Head Neck Surg (United States). https ://doi.org/10.1177/0194599820920850

37. Meccariello G, Gallo O (2020) What ENT doctors should know about COVID-19 contagion risks. Head Neck 42:1248-1249

38. Zhou R, Li F, Chen F et al (2020) Viral dynamics in asymptomatic patients with COVID-19. Int J Infect Dis 96:288-290. https://doi. org/10.1016/j.ijid.2020.05.030

39. Kong WH, Li Y, Peng MW et al (2020) SARS-CoV-2 detection in patients with influenza-like illness. Nat Microbiol 5:675-678. https://doi.org/10.1038/s41564-020-0713-1

40. Pan L, Mu M, Yang P et al (2020) Clinical characteristics of COVID-19 patients with digestive symptoms in Hubei, China. Am
J Gastroenterol 115:766-773. https://doi.org/10.14309/ajg.00000 00000000620

41. Helms J, Kremer S, Merdji H et al (2020) Neurologic features in severe SARS-CoV-2 infection. N Engl J Med. https://doi. org/10.1056/nejmc2008597

42. Hogikyan ND, Shuman AG (2020) Otolaryngologists and the doctor-patient relationship during a pandemic. Otolaryngol Head Neck Surg. https://doi.org/10.1177/0194599820922990

Publisher's Note Springer Nature remains neutral with regard to jurisdictional claims in published maps and institutional affiliations. 